\title{
Can common finishing treatments used in chef jacket fabrics improve protection against scald injury?
}

\author{
Sushmitha Devarajan, Rachel H. McQueen* and ShuQin Wen
}

\author{
*Correspondence: \\ rachel.mcqueen@ualberta.ca \\ Department of Human \\ Ecology, University of Alberta, \\ Edmonton, AB T6G 2N1, \\ Canada
}

\begin{abstract}
Chefs and other food preparation workers are at a high risk of scald injuries from hot liquids. Chefs' clothing has the potential to act as a protective barrier between the skin and the thermal hazard. Although, impermeable barriers coupled with an insulating layer of fabric tend to offer the greatest protection against hot liquid penetration, the potential for heat strain and discomfort to workers may make them impractical in the kitchen environment. This study examined the effects of common finishing treatments used in chef jacket fabrics and the impact of layers on the protection offered against hot water burn injuries. The Teflon ${ }^{\circledR}$ treated fabrics offering combined stain and water repellency, provided the greatest protection with the lowest absorbed energy and longest times to second degree burn injury compared with the other finishes (i.e., regular, water repellent and soil release). Findings also showed that in most cases, increasing the number of layers improved protection provided by the fabric systems, with the Teflon ${ }^{\circledR}$ finished fabrics providing the highest protection against scald injuries as fabric layers increased.
\end{abstract}

Keywords: Chef's jackets, Hot water splash protection, Burn injury, Absorbed energy, Fabric finishing, Layering

\section{Introduction}

Cooking and food handling procedures in restaurants involve workers being in close proximity to hot equipment, flame, hot liquids and steam. As such, it is not surprising that burn injuries within food preparation and service workers have been reported as being among the highest of all occupational groups (Islam et al. 2000; Walters 2009). Burns and scalds have been reported as being the third most common type of injury, sustained by cooks and food service workers, after strains/sprains and cuts/lacerations (Cann et al. 2008; Gleeson 2001; Pearsonick 1991). Among injuries sustained by cooks and other food service workers scalds have accounted for around $60 \%$ of all burn injuries (Islam et al. 2000; Reichard et al. 2015). It is important to note, that many scald injuries within the kitchen environment will go unreported due to not being severe enough to warrant medical attention, however in many cases they may still cause pain and limit productivity. 
Clothing worn by chefs has the potential to offer protection against thermal hazards in the kitchen environment. The chef's jacket, particularly those of a double-breasted design, has been reported as providing protection against heat within the kitchen (Culinary Institute of America 2001). However, chef's clothing is typically made from air permeable, woven fabrics composed of either $100 \%$ cotton or polyester/cotton blends which do not tend to have flame retardant properties and are not deemed to be protective per se. In a recent examination of fabrics taken from commercially available chefs' jackets, minimal protective capability of single-layer fabrics against hot surface contact, hot water and low-pressure steam burns was found, with time to predicted second degree burn injuries occurring in less than $2 \mathrm{~s}$ (Zhang et al. 2015). In other research on chemical protective clothing 5-10 s was considered short for protection against burns from hot liquid (Stull and McManus 2004). Therefore, this highlights that a typical chef's uniform fabric has very low, or no, protection value.

There have been several studies investigating the performance of various permeable, semi-permeable and impermeable fabrics and garments used in high-risk industries (e.g., oil and gas, fire-fighting), where flame retardant protective apparel is essential but hot water and steam hazards can also be present (e.g., Jalbani et al. 2012; Lu et al. 2013a, 2015a, b; Mandal et al. 2013). Impermeable fabrics have been shown to offer the highest protection against hot liquids, with semi-permeable fabrics offering better protection than permeable fabric systems (Jalbani et al. 2012; Lu et al. 2013a; 2015a). Mandal et al. (2013) reported that fabric thickness was positively correlated with predicted time to second degree burn injuries from hot water, yet air permeability of the fabric system had a greater influence (Mandal et al. 2013). Air permeability has also been noted to be important in other studies, where fabrics with higher air permeability offered lower protection against hot liquids (Gholamreza and Song 2013; Jalbani et al. 2012). However, in a comparison of permeable fabrics with respect to hot liquid penetration, one fabric with a high contact angle (and therefore lower surface energy so enhanced liquid repellency) had lower penetration with hot liquids compared to two other fabrics that had lower air-permeability (Lu et al. 2014).

In certain circumstances, an approach to increasing the level of thermal protection in a clothing system can be to increase the numbers of the layers. This is because the effective thickness of the clothing system is increased with increasing number of layers, as well as an increase in insulation through the addition of air gaps between the layers. For example, Zhang and colleagues (2015) found that by layering fabrics the predicted skin-burn injury time was increased with exposure to a hot surface. However, in other circumstances, the increase in layers can reduce thermal protection. For example, predicted time to second-degree burn injury did not increase for all fabric systems under evaluation with the addition of another air-permeable layer for low-pressure steam or $85{ }^{\circ} \mathrm{C}$ hot water (Zhang et al. 2015a, b). This was likely due to the fact that liquid and steam penetrated the air-permeable fabric system rapidly and there was an increase in the amount of thermal energy being stored within the thicker fabric system thereby increasing the intensity of burns (Song et al. 2011). When a liquid repellent, air-impermeable apron layer was positioned as the outermost layer on the fabric system no second-degree burn injury was predicted during the $60 \mathrm{~s}$ test period (Zhang et al. 2015a, b). 
Heat and humidity generated from cooking equipment can result in the ambient temperature within the kitchen reaching up to $30{ }^{\circ} \mathrm{C}$ (Haruyama et al. 2010; Maguire and Howard 2001). These high ambient temperatures within the kitchen have been recorded as being the highest during the busiest times for customer service (i.e., lunch, dinner) (Maguire and Howard 2001). The associated work-related activities at these times would result in the highest metabolic heat production, further increasing the potential for overexertion and heat strain. Therefore, it is important when considering improving thermal protection against hot liquids for chefs' clothing, that the thermal comfort of the wearer is not compromised. Air impermeable clothing worn in a hot working environment can prevent evaporative heat loss of sweat from the body potentially leading to heat stress (Holmér 2006). The typical fabrics used in chef's jackets are air permeable but as such are less likely to provide a protective barrier against hot liquids (Zhang et al. 2015b).

Different types of finishes can be applied to fabrics used in chef's clothing, mostly to offer resistance to soiling and make care of the clothing easier (e.g., stain repellency, wrinkle resistance, soil release finishes) (Chefwear 2012). Repellent finishes applied to a fabric, opposed to a waterproof membrane or coating, are particularly important when an important characteristic of the fabric is that it remains permeable to air, and hence allows water vapor to easily permeate (Gibson 2006; Holme 1993). Therefore, finishes which impart repellency to water and other liquids could also offer protection against scald injuries as hot water and other hot liquids may bead and run off the fabric rather than being absorbed into the fabric. Soil-release finishes, intended to make laundering more effective may be applied to fabrics with polyester fibers or wrinkle-resistant treated cotton fabrics. Since most soils are hydrophobic, the soil-release finishes tend to make the fiber surface more hydrophilic and thereby allow the diffusion of water and detergent into the soil-fiber interface and decreases the adhesion of the soil to the fibers (Holme 1993; Kissa 1981). Fluorochemicals are the most interesting class of chemical for textile finishing as they provide combined water and oil repellency to fabrics (Holme 1993). Teflon ${ }^{\circledR}$ is the best known polytetrafluoroethylene which is used for its water-repellent properties and labeled 'superhydrophobic'. Its low coefficient of friction with many materials makes it 'non-stick' and is commonly used in cookware (Nilsson et al. 2010). For textiles to be used in scald protection, they should possess high water contact angles and low sliding angles so that the surface of the fabrics are slippery causing the water droplets to roll off from the surface of the fabric. These superhydrophobic fabrics are known to exhibit high repellency to cool water $\left(25^{\circ} \mathrm{C}\right)$, but with increasing water temperature, the surface tension decreases and hence repellency can be significantly lowered particularly to pressurized hot liquid (Liu et al. 2009). This was evident in the research by Lu et al. (2014), who found that liquid penetration (distilled water, canola oil, drilling fluid) through selected industrial fabrics increased as temperature increased $\left(27,55,85^{\circ} \mathrm{C}\right)$.

The purpose of this study was to examine the effect of finishing treatment and layering on the protection of plain and twill weave fabrics commonly used in chef's jackets against hot water burn injury. Fabric chemical finishes can have a major impact on the final performance of a textile fabric. Therefore, it was hypothesized that there would be a significant difference in the hot-water protection provided by fabrics treated with a performance finish (i.e., water-repellent, soil-release, combined water/stain repellent) compared with fabrics that had not been given a special performance finish (untreated). 
Furthermore, it was hypothesized increasing the number of fabric layers would increase the level of protection against hot water afforded by the fabrics.

\section{Methods}

\section{Fabrics and fabric preparation}

Eight fabrics composed of $65 \%$ polyester $35 \%$ cotton were selected for this study. Descriptions of the fabrics are provided in Table 1. Four different types of finishes were applied to the fabrics-namely soil release finish, water resistant finish, Teflon ${ }^{\circledR}$ finish (combined stain and water repellent finish) and a regular finish fabric (no treatment). The study also included the effect of increasing the number of layers of fabric $(1,2$ and 3 layers) on providing thermal protection to the wearer against hot water splashes. The fabrics were sourced from Unisync Group Limited (Mississauga, ON, Canada) and represent a select range of fabrics that are used in chefs' jackets. As the fabric finishing treatments were proprietary no further details beyond the fabric finishing type/label was provided.

All fabrics were laundered according to CAN/CGSB-4.2. No.58-2004 Procedure IIIE with a moderate wash temperature of $50 \pm 2{ }^{\circ} \mathrm{C}$ with a concentrated detergent Tide ${ }^{\circledR}$, followed by tumble drying to relax the fabric structures. Test specimens were cut so that no 'like' specimens had the same warp and weft yarns. Prior to testing, the test samples were conditioned for $24 \mathrm{~h}$ according to CAN/CGSB-4.2 No.2-M88 in standard conditions at $20 \pm 2{ }^{\circ} \mathrm{C}$ and $65 \pm 2 \%$ relative humidity (R.H.).

\section{Experimental design}

A $2 \times 4 \times 3$ factorial design was carried out using the polyester/cotton fabrics against hot water splash. In this three-way factorial design, the independent variables consisted of two different fabric structures (plain, twill), four different finish treatments (no treatment [regular], water repellent, soil release, combined stain and water repellent [Teflon ${ }^{\circledR}$ ] finish) and three arrangements of fabric layer (1 layer, 2 layers and 3 layers). The dependent variables were the absorbed energy (during $60 \mathrm{~s}$ data acquisition) and the time required to create a second-degree burn and a third-degree burn injury prediction

Table 1 Description of test fabrics

\begin{tabular}{|c|c|c|c|c|c|}
\hline Fabric code & Fabric structure & $\begin{array}{l}\text { Finishing } \\
\text { treatment }\end{array}$ & $\begin{array}{l}\text { Mass per unit } \\
\operatorname{area}^{a}\left(g / m^{2}\right)\end{array}$ & $\begin{array}{l}\text { Thickness } \\
\text { (mm) }\end{array}$ & $\begin{array}{l}\text { Fabric count }^{c} \\
\text { (warp/cm } \times \text { weft } / \\
\mathrm{cm})\end{array}$ \\
\hline P0 & Plain & None & 189 & 0.36 & $44 \times 21$ \\
\hline PW & Plain & Water repellent & 192 & 0.38 & $44 \times 22$ \\
\hline PS & Plain & Soil release & 189 & 0.37 & $44 \times 22$ \\
\hline PT & Plain & Teflon ${ }^{\circledR}$ & 189 & 0.37 & $44 \times 22$ \\
\hline TO & Twill & None & 272 & 0.53 & $50 \times 25$ \\
\hline TW & Twill & Water repellent & 251 & 0.47 & $49 \times 24$ \\
\hline TS & Twill & Soil release & 276 & 0.56 & $47 \times 26$ \\
\hline $\mathrm{TT}$ & Twill & Teflon $^{\circledR}$ & 245 & 0.44 & $49 \times 23$ \\
\hline
\end{tabular}

a CAN/CGSB-4.2 No.5.1-M90

b CAN/CGSB-4.2 No.37-2002

c CAN/CGSB-4.2 No.6-M89 
following exposure to hot water splash at $85{ }^{\circ} \mathrm{C}$. Air permeability for all the eight different fabric types was also measured in 1, 2 and 3 layers combinations.

\section{Hot liquid splash test}

Thermal performance of the textile materials under hot water was measured following a modified version of the ASTM F2701-08 Standard Test method for evaluating heat transfer through materials for protective clothing upon contact with a hot liquid splash. The ASTM F2701-08 method involved pouring hot water on the textile material through a funnel for $10 \mathrm{~s}$. However, manually pouring hot water over the fabric was found to affect the repeatability and the flow rate of water (Jalbani et al. 2012). Hence, the test apparatus and the method described in Jalbani et al. (2012) was used which involved circulating hot water through a small pipe from the hot water bath. In this method, the flow of hot water through the pipe could be adjusted by a valve and therefore a consistent flow rate and temperature could be maintained throughout the test.

The fabrics to be tested were placed on a sensor board which was inclined at 45 degrees. Three sensors on the sensor board were positioned on the upper, lower and the middle positions and the temperature readings on each of the sensors were monitored. The outlet of the hot water was placed in such a way that the hot water directly splashes on the upper sensor and the sensor measured the thermal energy transferred through the specimen. The time taken to pour $1000 \mathrm{ml}$ of water on the test fabric were determined at the beginning of the study and adjustments were made to provide a flow rate of $1000 \mathrm{ml}$ in $10 \mathrm{~s}$. Data were recorded during the $10 \mathrm{~s}$ exposure time and for $50 \mathrm{~s}$ after the exposure to the hot water ( $60 \mathrm{~s}$ recording time in total). Heat flux was recorded during this time and total absorbed energy was calculated from heat flux data. The time in seconds taken to reach a predicted second- and third-degree burn was based on a multi-layer skin model (Lu et al. 2013a). If no burn occurred during the $60 \mathrm{~s}$ test period a no burn (NB) was recorded. Five replications for each fabric sample were carried out and the order of testing fabric systems was randomized.

\section{Air permeability}

Air permeability of fabrics was measured in accordance with CAN/CGSB-4.2 No.362002. The testing device used in this experiment was a Frazier high-pressure air permeability apparatus. The air pressure differential was adjusted to $12.7 \mathrm{~mm}$ of water gauge pressure (125 Pa). Ten replicates of each fabric system were tested.

\section{Statistical analysis}

Mean (M) and standard deviation (SD) were calculated for absorbed energy and time to second- and third-degree burn for the top, middle and lower sensors. Statistical analysis was performed by using Statistical Package for the Social Sciences (SPSS) Software (version 21.0). A three-way analysis of variance (ANOVA) was used to analyze the effect of fabric type, finish and number of fabric layers on time to second-degree burn and absorbed energy for upper, middle and lower sensors. For ANOVA on the time to second-degree burn the data was $\log _{10}$ transformed to meet assumptions of normality. Third degree burn results were not used for the analysis as many of the fabric 
combinations did not reach the third degree burn criteria during the hot water exposure tests. Post-hoc comparisons were made using Tukey HSD test on data.

\section{Results and discussion}

The mean and standard deviation for absorbed energy and second and third degree skin prediction burn injury time is provided in Table 2 for all sensors. Figures 1 and 2 shows the absorbed energy and predicted time to second-degree burn injury, respectively, for the upper sensor. Air permeability of the 1-, 2- and 3-layered fabric systems are shown in Fig. 3.

\section{Effect of fabric finish}

Fabric finish was one of the most significant variables influencing absorbed energy (Upper sensor: $\mathrm{F}_{3,96}=214.41, p \leq 0.001$; Middle sensor: $\mathrm{F}_{3,96}=40.386, p \leq 0.001$; Lower sensor: $\left.\mathrm{F}_{3,96}=67.65, p \leq 0.001\right)$ and time to second-degree burn for the upper sensor $\left(\mathrm{F}_{3,95}=20.67, p \leq 0.001\right)$. At the upper sensor, Teflon ${ }^{\circledR}$ treated fabrics had the lowest absorbed energy $\left(150.9 \pm 30.5 \mathrm{~kJ} \mathrm{~m}^{-2}\right)$ and the highest mean time to second-degree burn $(6.3 \pm 2.9 \mathrm{~s})$ overall, which differed significantly from all other finishes with the upper sensor absorbed energy mean values ranging from 245.2 to $253.3 \mathrm{~kJ} \mathrm{~m}^{-2}$ (for water resistant and soil release treatments respectively). As many of the 3-layer fabric systems did not meet the criteria needed to predict a second-degree burn, a separate analysis of just the 1- and 2-layered fabric systems for the middle and lower sensors was carried out. The effect of finish was not significant for the middle sensor results $\left(\mathrm{F}_{3,64}=0.32\right)$ but was for the lower sensor $\left(\mathrm{F}_{3,64}=2.79, p \leq 0.05\right)$. Although, not included in the ANOVA it is important to note that in the 3-layer configuration more twill-weave Teflon ${ }^{\circledR}$ treated fabrics did not meet the second-degree burn criteria compared with the other fabric combinations. None of the Teflon ${ }^{\circledR}$ treated fabrics met the third-degree burn criteria even as a single layer (see Table 2). Whereas, all other fabrics as a single or double layered system reached a third degree burn for at least one specimen.

Despite, no differences being detected for second-degree burn at the middle sensor among fabric finish it is clear that the Teflon ${ }^{\circledR}$ treatment provides both plain and twill weave fabrics with greater protection against hot water penetration. Teflon ${ }^{\circledR}$ finishes may be applied to fabrics to make them hydrophobic and offer repellency to both water and oil. Repellency of the Teflon ${ }^{\circledR}$ treated surface to cold water has been well documented (Nilsson et al. 2010; Wi et al. 2009), but less so to hot water (Liu et al. 2009). In fact, Liu et al. (2009) found that a reduction in water repellency occurred as the water temperature was increased, which was due to the decrease in surface tension of hot water (Liu et al. 2009). In the current study, the surface tension of the fabrics to hot or cold water was not carried out. However, the results in the current study do show that the combined stain and water repellent Teflon ${ }^{\circledR}$ treatment can provide some protection from hot water exposure. Interestingly the Teflon ${ }^{\circledR}$ twill fabric had the highest air permeability (Fig. 3) of all the fabrics which may be explained by its lower mass and thickness (see Table 1). Therefore, the Teflon ${ }^{\circledR}$ treatment is unlikely to compromise thermal-related comfort properties as air permeability is an important predictor of thermal comfort (Epstein et al. 2013; Hatch et al. 1990) and well correlated with water vapor diffusion (Wen et al. 2012). The finding that fabric properties such as the ability of a fabric to repel 


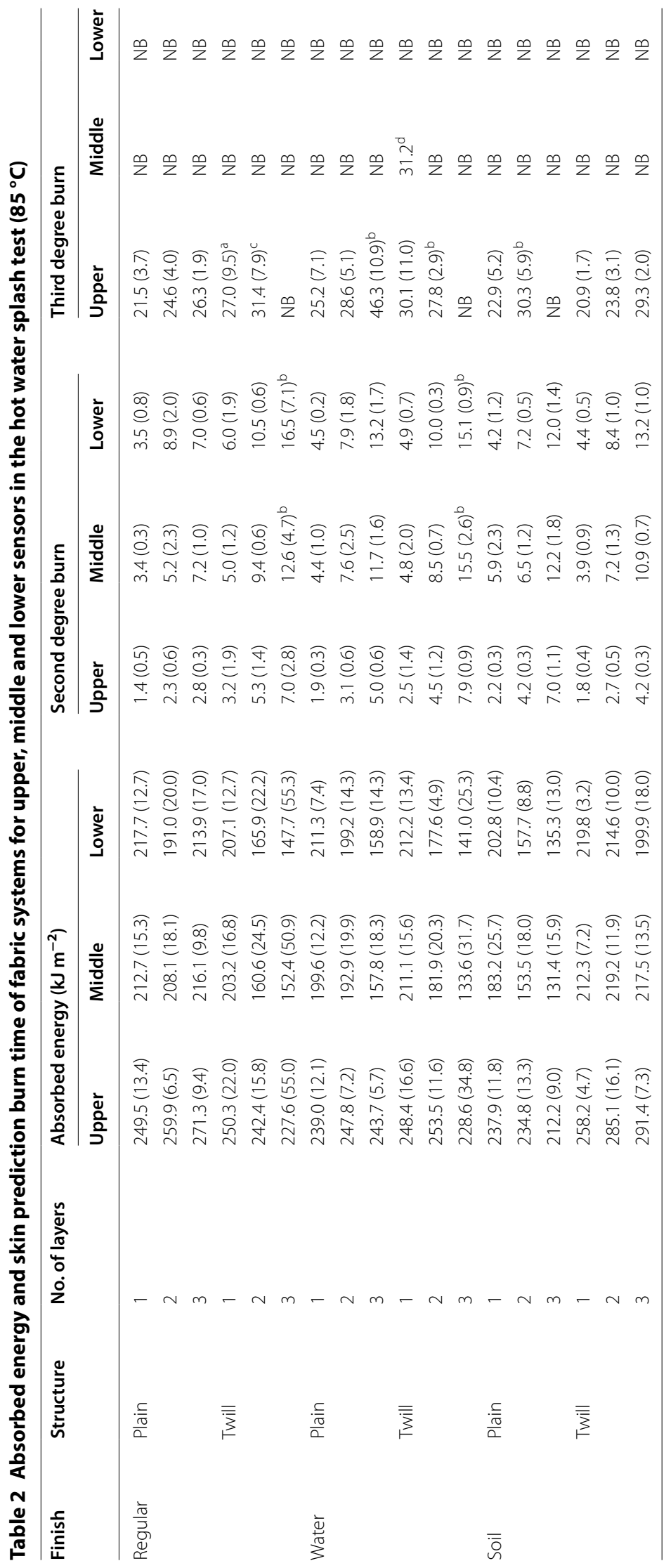




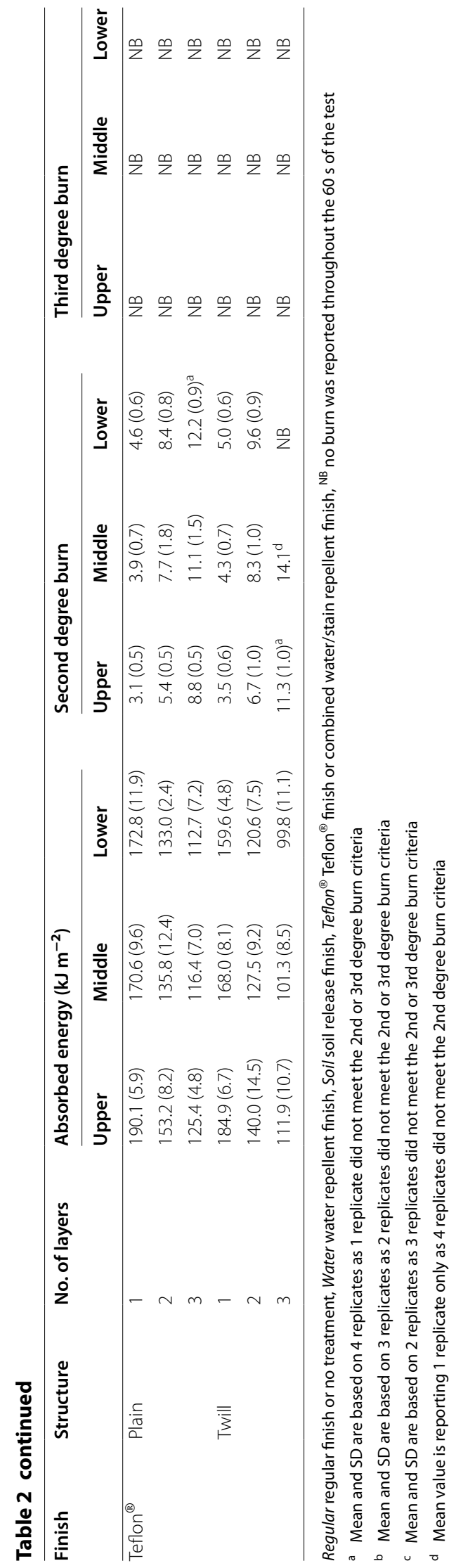




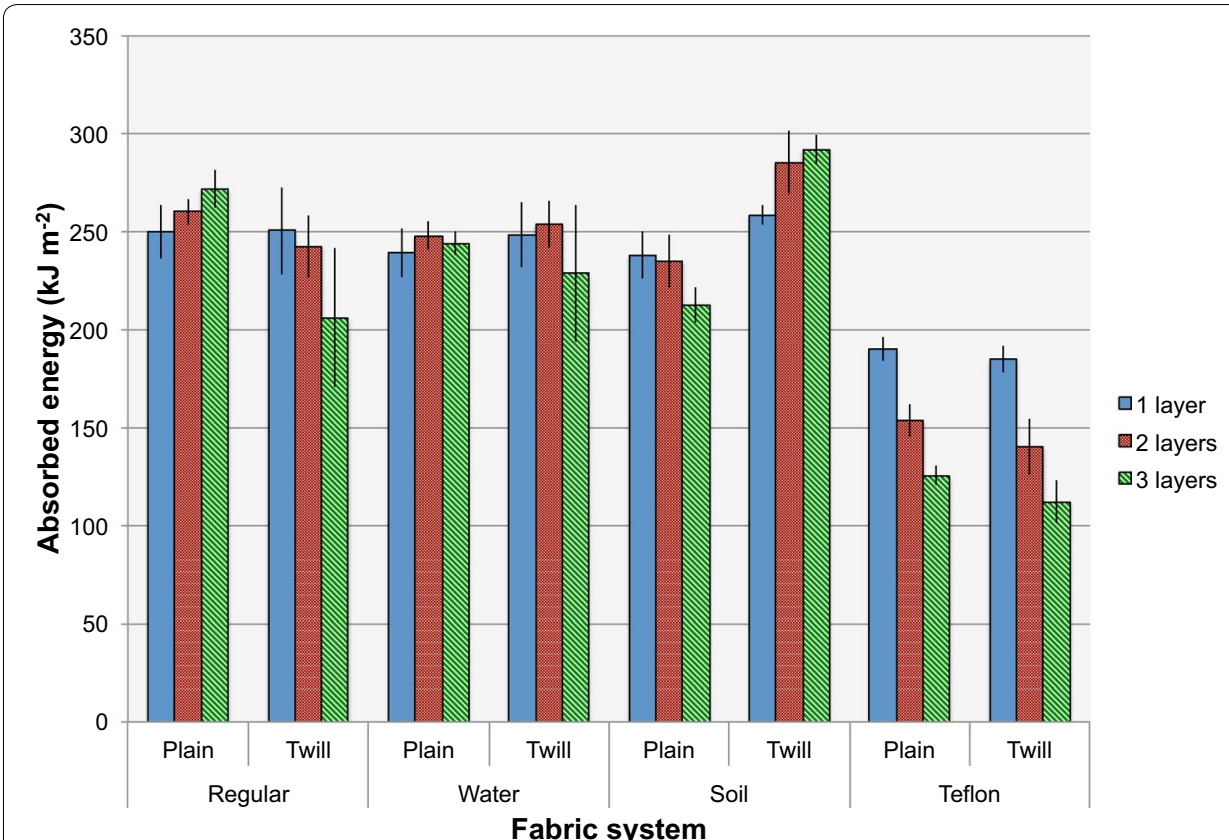

Fig. 1 Absorbed energy (mean \pm SD) of fabric systems against hot water exposure at $85^{\circ} \mathrm{C}$ for upper sensor

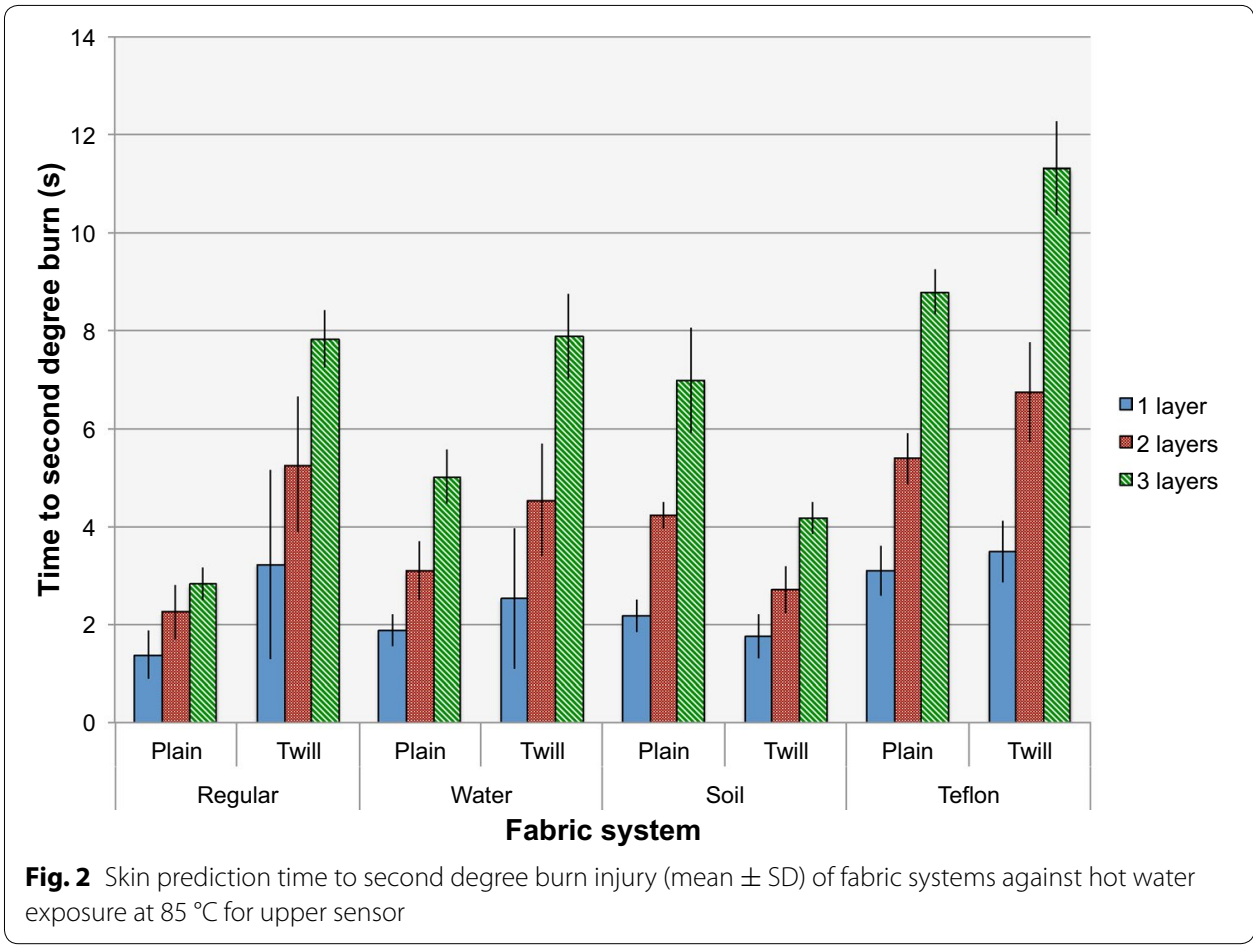

liquid may be more important than how porous it is (as indicated by air permeability) has also been found in other research. For example, one permeable fabric ( $40 \% \mathrm{Kevlar}^{\circledR}$ aramid/60\% polybenzimidazole) had lower surface energy but higher air permeability than two other fabrics examined ( $100 \%$ cotton; $88 \%$ cotton $/ 12 \%$ nylon) yet it exhibited 


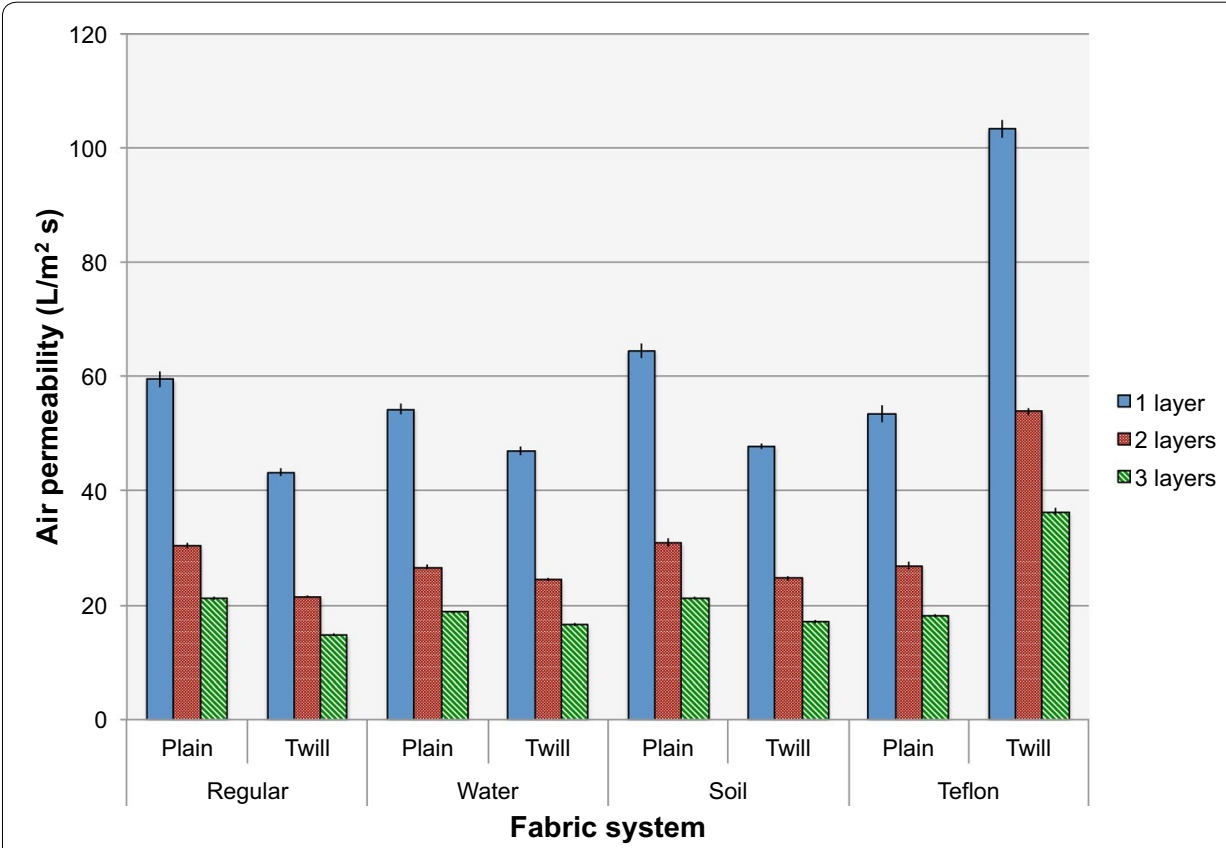

Fig. 3 Air permeability (mean \pm SD) of fabric systems

longer times to predicted second-degree burn injury and lower penetration of hot liquids (Lu et al. 2013c, 2014).

It is important to note that the fabrics in the current study were laundered once prior to any experimental being conducted, whereas, in use chefs' clothing would be repeatedly laundered. The durability of the finishing treatment applied to a fabric is vital to maintain the necessary performance properties of water/stain repellency or soil release (Gibson 2006; Holme 1993). The durability of the finishing treatments to repeated laundering was not assessed in this study.

\section{Effect of fabric}

The test fabrics in this study differed from one another by fabric structure and inherent fabric properties such as mass per unit area and thickness. The twill weave fabrics were heavier and thicker than the plain weave fabrics. Therefore, any differences in hot water repellency between the twill and plain weave fabrics were more likely to result from differences in thickness and weight rather than fabric structure per se. As a main effect, there were no significant differences for absorbed energy between the twill and plain weave fabrics at any of three sensor locations. However, fabric structure did have an effect on predicted second-degree burn time at the upper sensor $\left(\mathrm{F}_{1,95}=8.96, p \leq 0.01\right)$, and at the middle sensor $\left(\mathrm{F}_{1,95}=4.32, p \leq 0.05\right)$ and the lower sensor $\left(\mathrm{F}_{1,64}=15.98, p \leq 0.001\right)$ (for 1 and 2 layers only). This means when the mean values of plain and twill fabrics were compared, overall the twill fabrics took longer to reach a predicted second-degree burn compared with the plain weave fabrics (e.g., $4.9 \pm 2.8 \mathrm{~s}$ compared with $4.0 \pm 2.2 \mathrm{~s}$ respectively at the upper sensor). This may be in part due to the fact that it takes longer for the hot water to penetrate the thicker fabric to elicit a large enough temperature rise to create 
a burn injury. Yet, during the $60 \mathrm{~s}$ data acquisition time $(10 \mathrm{~s}$ hot water exposure and $50 \mathrm{~s}$ after exposure), the total amount of energy absorbed by the sensors were not significantly different between the plain and twill fabric groups. The explanation for this is that although the thicker twill fabric lowered the peak heat flux of hot water penetration and conductive heat at the beginning of the tests, in the rest of the test, the amount of energy released from the twill fabric was more than that from the thinner plain fabric since more hot water and heat was absorbed by and stored in the twill structure. As a result of these combined effects, the total absorbed energy, which is the area below the heat flux curve illustrated in Fig. 4, did not differ between the plain and twill groups. This effect has also been noted in other studies (e.g., Zhang et al. 2015a).

When each individual treatment group was considered, there was an interesting finding on the soil release group. The plain woven soil release fabric was found to have a significantly longer time to second degree burn $(4.5 \pm 2.1 \mathrm{~s})$ than the twill woven soil release fabric $(2.9 \pm 1.1 \mathrm{~s})\left(\mathrm{F}_{3,95}=13.27, p \leq 0.001\right)$, which was the inverse of the overall effect of fabric type on time to second degree burn. The plain woven soil release fabric also had a significantly lower total absorbed energy for all layers $\left(228.3 \pm 15.9 \mathrm{~kJ} \mathrm{~m}^{-2}\right)$ than the twill woven soil release fabric $\left(278.2 \pm 17.8 \mathrm{~kJ} \mathrm{~m}^{-2}\right)$ at the upper sensor $\left(\mathrm{F}_{3,96}=21.94, p \leq 0.001\right)$. This significant interaction between fabric type and finish was due to the presence of the soil release finish. Typically the heavier-weight twill-weave fabrics offered better protection against predicted burn injury than plain weave fabrics. The soil release finish fabric was the exception to this trend. Soil release finishes applied to the fabric diffuses water under the soil to help remove this soil during laundering (Kissa 1981). The higher absorbed energy found for the twill weave fabrics may be due to the nature of the finish as the soil-release finish has the ability to reabsorb and remove

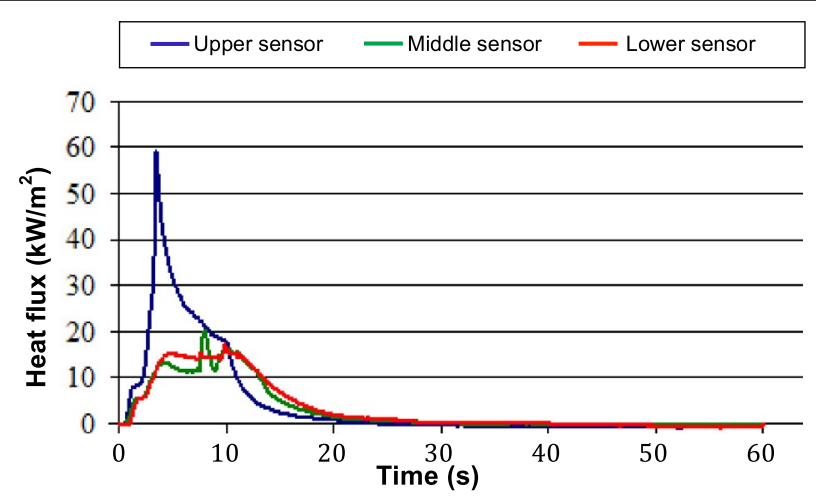

a 2-layer plain fabric with water repellent treatment

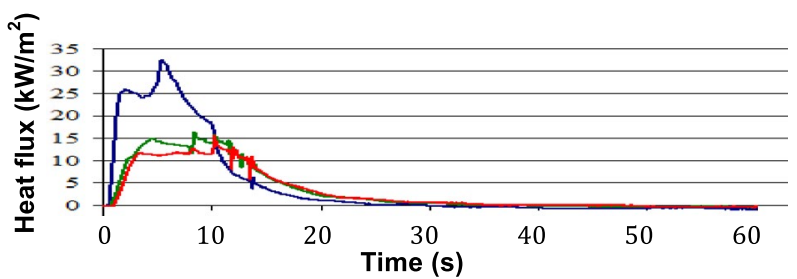

b 2-layer twill fabric with water repellent treatment

Fig. 4 Heat flux versus time during hot water tests on water-repellent fabrics 
soil from the fabric (Kissa 1981). This process of drawing in moisture may be the reason for absorbing more energy. As the twill woven fabrics are heavier and thicker than the plain woven fabrics it is possible that this added effect of absorbing more hot liquid made the twill fabrics store more energy than the plain fabrics.

\section{Effect of layering}

Layering of fabrics also had a significant effect on both absorbed energy $\left(F_{2,96}=9.62\right.$, $p \leq 0.001)$ and the time to create a second degree burn injury $\left(\mathrm{F}_{2,95}=115.60, p \leq 0.001\right)$. As the number of layers increased the time to second degree burn increased (e.g., overall mean for all fabrics/finishes on the upper sensor: 1 layer: $2.5 \pm 1.2 \mathrm{~s}$; 2 layers: $4.3 \pm 1.6 \mathrm{~s}$; 3 layers: $6.5 \pm 2.8 \mathrm{~s}$ ). This was consistent for all fabric and finishing treatments. For some fabric systems however, the total absorbed energy increased as the number of layers increased. Of the fabric/finishes that increased in absorbed energy (i.e., P0, PW, TS) the only significant difference noted for layers were for the twill soil-release fabric where the single-layer fabric system was significantly lower $\left(258.2 \pm 4.7 \mathrm{~kJ} \mathrm{~m}^{-2}\right)$ than the 2and 3-layered fabric systems (i.e., $285.1 \pm 16.1 \mathrm{~kJ} \mathrm{~m}^{-2}$ and $291.4 \pm 7.3 \mathrm{~kJ} \mathrm{~m}^{-2}$ respectively). Overall, the 3-layered fabric systems were significantly lower in absorbed energy $\left(215.3 \pm 65.9 \mathrm{~kJ} \mathrm{~m}^{-2}\right)$ than the 1- and 2-layered fabric systems $\left(233.2 \pm 29.9 \mathrm{~kJ} \mathrm{~m}^{-2}\right.$ and $227.1 \pm 50.4 \mathrm{~kJ} \mathrm{~m}^{-2}$ respectively).

Increasing the number of layers essentially increases the thickness of the fabric system and when the fabric had a finish which repelled hot water the increasing thickness increased predicted second-degree burn time and decreased the total energy absorbed by the fabric system. This was evident with the Teflon ${ }^{\circledR}$ treated fabrics (see Fig. 1 and Table 2) where total absorbed energy reduced with additional fabric layers. The mean time to predicted second-degree burn for the upper sensor was $8.8 \pm 0.5 \mathrm{~s}$ for plain Teflon ${ }^{\circledR}$ 3-layered fabric system and $11.3 \pm 1.0 \mathrm{~s}$ for four replicates of the twill Teflon ${ }^{\circledR}$ 3-layered fabric system. The fact that one replicate for the twill Teflon ${ }^{\circledR} 3$-layered fabric system did not reach the second-degree burn criterion is evidence that this 3-layered system provides good protection against hot-water splash. The upper sensor is directly below the water stream and provides the greatest amount of pressure from the water during the first $10 \mathrm{~s}$ of water release. The middle and lower sensors are further down the $45^{\circ}$ inclined sensor board and the pressure from the hot water is considerably lower. It is important to note that in the twill Teflon ${ }^{\circledR}$ 3-layered system only one replicate reached the second-degree burn criterion at the middle sensor and no specimens registered a second-degree burn criterion during the $60 \mathrm{~s}$ test period at the lower sensor. For all other fabric/finishes, the 3-layered fabric system also offered significantly longer seconddegree burn times than the 2-layered or 1-layered systems at the middle and lower sensors (with the exception of the lower sensor for the plain regular fabric system). There is no doubt that the Teflon ${ }^{\circledR}$ treatment in a 3-layered configuration offers the highest protection of the fabrics examined in this research. Lu et al. (2013) discuss the mass and heat transfer as $85^{\circ} \mathrm{C}$ hot water is challenged to various permeable, semi-permeable and impermeable fabrics. "Most of the liquid spreads and flows away along the fabric surface" (p. 41) but they also noted that some of the liquid penetrates the fabric, as well as some vapor transfer occurs (Lu et al. 2013a). As the fabrics in the current study were all permeable to air, all three mechanisms will be occurring. However, for the Teflon ${ }^{\circledR}$ 
treated fabrics more mass of hot liquid will flow along the surface running off the fabric. With increasing layers of fabric, less liquid penetrated the entire system as well as less conductive heat transferred to the sensors, increasing the time to predicted burn injury and reducing the amount of energy absorbed. The thickness of the 3-layered system increased the insulating effect of the fabric. Increasing fabric layers however, has the negative effect of increasing the thermal burden to the wearer as increased thickness is associated with higher thermal insulation and lower evaporative resistance (Kilinc-Balci 2011) and as shown in Fig. 3, decreasing air permeability. With this in mind, fabric layering may still be considered a solution for key areas of the chef's jacket that require greater protection, such as the arms, particularly the forearms as they have been reported as being the region of high risk of burn injury (Halpin et al. 2008; Islam et al. 2000).

\section{Conclusions}

The purpose of this research was to examine whether various selected finishing treatments which may be applied to plain and twill weave fabrics used for chefs' jackets can offer the potential for protection against scald injuries, as well as examining the impact of layering fabrics. Results showed that the Teflon ${ }^{\circledR}$ finished fabrics which offer combined water and stain repellency had the longest time to predicted skin burn injury and lowest absorbed energy compared with all other fabric finishes. Increasing the numbers of layers of the Teflon ${ }^{\circledR}$ finished fabrics has the greatest potential for providing good protection against scald injuries as much of the water in a hot-water splash runs off the repellent fabric surface. None of the Teflon ${ }^{\circledR}$ treated fabric systems reached the predicted third-degree burn criterion, even as a single layered system, whereas, all other fabric/finishes met the third-degree burn criterion as a single and sometimes doublelayered system. Conflicting results were evident for the soil-release finish, which lowered the protective performance in twill weave fabrics, but increased protection in the plain weave fabrics (compared to regular finished fabrics). With the exception of soilrelease finishes, the heavier weight twill weave fabric offered longer times to predicted second-degree burn and lower absorbed energy, than the lighter weight plain weave fabrics. Furthermore, the addition of another layer to the fabric system tended to increase the potential protective performance of the fabric systems for most fabric finishes, although decreasing the air permeability. There is clear evidence in this research of the benefit of applying a Teflon ${ }^{\circledR}$ finish to chef's clothing, not only to improve repellency against oil and water-borne stains, but also as a means to improve protection against hot water splash. The Teflon ${ }^{\circledR}$ finish maintains a level of thermal comfort which is currently accepted in chef's clothing. Further work to determine whether Teflon ${ }^{\circledR}$ would also increase protection against hot oils and steam is recommended, as well as the durability of the treatment to repeated laundering.

\section{Authors' contributions}

SD planned the research, conducted the hot water splash tests and wrote the first draft of the manuscript. RHM supervised the research and revised the manuscript. SW carried out air permeability tests and wrote sections in the manuscript. All authors read and approved the final manuscript.

\section{Acknowledgements}

We would like to thank Dr. Jane Batcheller and Mr. Stephen Paskluk for their help in the experimental work. We also acknowledge the Unisync Group Ltd for kindly supplying fabrics for this research. 
Competing interests

The authors declare that they have no competing interests.

\section{Publisher's Note}

Springer Nature remains neutral with regard to jurisdictional claims in published maps and institutional affiliations.

Received: 30 August 2016 Accepted: 4 May 2017

Published online: 28 September 2017

\section{References}

Cann, A. P., Baker, A. M., Hansen, A., Massie, D., \& Vandervoort, A. A. (2008). A five year retrospective analysis of occupational injuries and incidence reported at a research intensive Canadian university. Work, 30(2), 171-184

Chefwear. (2012). Which fabric is right for me? Retrieved January 11, 2015 from http://www.chefwear.com/news/article. asp?ARTICLE ID $=72 \&$.

Culinary Institute of America. (2001). The chef's uniform. Gastronomica: The Journal of Critical Food Studies, 1(1), 88-91.

Epstein, Y., Heled, Y., Ketko, I., Muginshtein, J., Yanovich, R., Druyan, A., et al. (2013). The effect of air permeability characteristics of protective garments on the induced physiological strain under exercise-heat stress. Annals of Occupational Hygiene, 57(7), 866-874. doi:10.1093/annhyg/met003.

Gholamreza, F., \& Song, G. (2013). Laboratory evaluation of thermal protective clothing performance upon hot liquid splash. The Annals of Occupational Hygiene, 57(6), 805-822. doi:10.1093/annhyg/met028.

Gibson, P. (2006). Water-repellent treatment on military uniform fabrics physiological and comfort implications. Journal of Industrial Textiles, 38(1), 43-54. doi:10.1177/1528083707087833.

Gleeson, D. (2001). Health and safety in the catering industry. Occupational Medicine, 51(6), 385-391. doi:10.1093/ occmed/51.6.385.

Halpin, J., Forst, L., \& Zautke, J. (2008). Conditions causing burn injuries in foodservice workers. Journal of Foodservice, 19(3), 189-193. doi:10.1111/j.1745-4506.2008.00099.x.

Haruyama, Y., Muto, T., Matsuzuki, H., Ito, A., Tomita, S., Muto, S., et al. (2010). Evaluation of subjective thermal strain in different kitchen working environments using subjective judgment scales. Industrial Health, 48(2), 135-144. doi:10.2486/indhealth.48.135.

Hatch, K. L., Woo, S. S., Barker, R. L., Radhakrishnaiah, P., Markee, N. L., \& Maibach, H. I. (1990). In vivo cutaneous and perceived comfort response to fabric: part l: thermophysiological comfort determinations for three experimental knit fabrics. Textile Research Journal, 60(7), 405-412. doi:10.1177/004051759006000705.

Holme, I. (1993). New developments in the chemical finishing of textiles. Journal of the Textile Institute, 84(4), 520-533. doi:10.1080/00405009308658985.

Holmér, I. (2006). Protective clothing in hot environments. Industrial Health, 44(3), 404-413. doi:10.2486/indhealth.44.404.

Islam, S. S., Nambiar, A. M., Doyle, E. J., Velilla, A. M., Biswas, R. S., \& Ducatman, A. M. (2000). Epidemiology of workrelated burn injuries: experience of a state-managed workers' compensation system. The Journal of Trauma, 49(6), 1045-1051.

Jalbani, S. H., Ackerman, M. Y., Crown, E. M., Keulen, M. Van, \& Song, G. (2012). Apparatus for use in evaluating protection from low pressure hot water jets. Journal of ASTM International, 9(4), 1-7. doi:10.1520/STP104098.

Kilinc-Balci, F. S. (2011). Testing, analyzing and predicting the comfort properties of textiles. In G. Song (Ed.), Improving Comfort in Clothing (pp. 138-158). Cambridge, UK: Woodhead Publishing.

Kissa, E. (1981). Mechanisms of soil release. Textile Research Journal, 51(8), 508-513. doi:10.1177/004051758105100803.

Liu, Y., Chen, X., \& Xin, J. H. (2009). Can superhydrophobic surfaces repel hot water? Journal of Materials Chemistry, 19(31), 5602-5611. doi:10.1039/b822168e.

Lu, Y., Song, G., Ackerman, M. Y., Paskaluk, S. A., \& Li, J. (2013a). A new protocol to characterize thermal protective performance of fabrics against hot liquid splash. Experimental Thermal and Fluid Science, 46, 37-45. doi:10.1016/j. expthermflusci.2012.11.018.

Lu, Y., Song, G., \& Li, J. (2013b). Analysing performance of protective clothing upon hot liquid exposure using instrumented spray manikin. Annals of Occupational Hygiene, 57(6), 793-804. doi:10.1093/annhyg/mes109.

Lu, Y., Song, G., Li, J., \& Paskaluk, S. (2013c). Effect of an air gap on the heat transfer of protective materials upon hot liquid splashes. Textile Research Journal, 83(11), 1156-1169. doi:10.1177/0040517512468809.

Lu, Y., Song, G., Li, J., \& Wang, F. (2015a). The impact of air gap on thermal performance of protective clothing against hot water spray. Textile Research Journal, 85(7), 709-721. doi:10.1177/0040517514553875.

Lu, Y., Song, G., \&Wang, F. (2015b). Performance study of protective clothing against hot water splashes: from bench scale test to instrumented manikin test. Annals of Occupational Hygiene, 59(2), 232-242. doi:10.1093/annhyg/meu087.

Lu, Y., Song, G., Zeng, H., Zhang, L., \& Li, J. (2014). Characterizing factors affecting the hot liquid penetration performance of fabrics for protective clothing. Textile Research Journal, 84(2), 174-186. doi:10.1177/0040517513485625.

Maguire, K., \& Howard, M. (2001). A study of the social and physical environment in catering kitchens and the role of the chef in promoting positive health and safety behaviour. International Journal of Environmental Health Research, 11(3), 203-217. doi:10.1080/09603120126720.

Mandal, S., Song, G., Ackerman, M., Paskaluk, S., \& Gholamreza, F. (2013). Characterization of textile fabrics under various thermal exposures. Textile Research Journal, 83(10), 1005-1019. doi:10.1177/0040517512461707.

Nilsson, M. A., Daniello, R. J., \& Rothstein, J. P. (2010). A novel and inexpensive technique for creating superhydrophobic surfaces using Teflon and sandpaper. Journal of Physics. D. Applied Physics, 43, 45301. doi:10.1088/0022-3727/43/4/045301

Pearsonick, M. E. (1991). Profiles in safety and health: eating and drinking places. Monthly Labor Review, 114(6), 19-26. 
Reichard, A. A., Konda, S., \& Jackson, L. L. (2015). Occupational burns treated in emergency departments. American Journal of Industrial Medicine, 58(3), 290-298. doi:10.1002/ajim.22407.

Song, G., Cao, W., \& Gholamreza, F. (2011). Analyzing stored thermal energy and thermal protective performance of clothing. Textile Research Journal, 81(11), 1124-1138. doi:10.1177/0040517511398943.

Stull, J. O., \& McManus, R. E. (2004). Evaluation of three chemical protective clothing materials for selected performance properties. Journal of ASTM International, 1(7), 1-12. doi:10.1520/STP12593S.

Walters, J. K. (2009). Characteristics of occupational burns in Oregon, 2001-2006. American Journal of Industrial Medicine, 52(5), 380-390. doi:10.1002/ajim.20689.

Wen, S., Song, G., \& Duncan, S. (2012). Analysis of physical and thermal comfort properties of chemical protective clothing. In A. M. Shepherd (Ed.), Performance of protective clothing and equipment: Emerging issues and technologies STP 1544 (pp. 48-73). West Conshohocken: ASTM International.

Wi, D. Y., Kim, I. W., \& Kim, J. (2009). Water repellent cotton fabrics prepared by PTFE RF sputtering. Fibers and Polymers, 10(1), 98-101. doi:10.1007/s12221-009-0098-5.

Zhang, H., McQueen, R. H., Batcheller, J. C., Ehnes, B. L., \& Paskaluk, S. A. (2015a). Characterization of textiles used in chefs' uniforms for protection against thermal hazards encountered in the kitchen environment. Annals of Occupational Hygiene, 59(8), 1058-1073. doi:10.1093/annhyg/mev034.

Zhang, H., McQueen, R. H., Batcheller, J. C., Paskaluk, S. A., \& Murtaza, G. (2015b). Clothing in the kitchen: evaluation of fabric performance for protection against hot surface contact, hot liquid and low-pressure steam burns. Textile Research Journal, 85(20), 2136-2146. doi:10.1177/0040517515581584.

\section{Submit your manuscript to a SpringerOpen ${ }^{\circ}$ journal and benefit from:}

- Convenient online submission

\section{- Rigorous peer review}

- Immediate publication on acceptance

- Open access: articles freely available online

- High visibility within the field

- Retaining the copyright to your article

Submit your next manuscript at $>$ springeropen.com 